\title{
In Haliotis, NO means YES
}

\section{Cory D. Bishop ${ }^{1 *}$ and William J. Biggers ${ }^{2}$ \\ ${ }^{1}$ Department of Biology, St. Francis Xavier University, Antigonish, NS, Canada \\ ${ }^{2}$ Department of Biology, Wilkes University, Wilkes-Barre, PA, USA \\ ${ }^{*}$ Correspondence: cbishop@stfx.ca}

\section{Edited by:}

Iliana B. Baums, The Pennsylvania State University, USA

Reviewed by:

Sandie M. Degnan, The University of Queensland, Australia

Rob Toonen, University of Hawaii at Manoa, USA

Keywords: metamorphosis, nitric oxide synthase, marine invertebrates, larval settlement, Mollusca

\section{A commentary on}

Nitric oxide is not a negative regulator of metamorphic induction in the abalone Haliotis asinina

by Ueda, N., and Degnan, S. M. (2014). Front. Mar. Sci. 1:21. doi: 10.3389/fmars. 2014.00021

Settlement and metamorphosis of marine invertebrate larvae is an ecological process of profound importance to the structure of benthic marine communities. Yet, metamorphosis is also a developmental process and our understanding of the mechanisms that regulate it remains relatively poor. Over the last 15 years, a nitric oxide (NO) based signaling system has emerged as the most phylogenetically widespread regulator of settlement and metamorphosis. Among a sea urchin, three sea squirts, three molluscs, a crustacean, and an annelid, NO (and often its downstream effector cGMP) regulates metamorphosis (Froggett and Leise, 1999; Bishop and Brandhorst, 2001; Bishop et al., 2001, 2006, 2008; Comes et al., 2007; Pechenik et al., 2007; Biggers et al., 2012; Zhang et al., 2012; Romero et al., 2013). Two important aspects to this pattern of NO function during metamorphosis are that (i) NO always acts as an inhibitory signal and that (ii) the functionality of NO signaling varies according to the settlement ecology of the larva. Ueda and Degnan's recent work has challenged the first pattern and supported the second.

First, why should NO signaling be inhibitory in these phylogenetically disparate, morphologically distinct (and, in some cases, CDB would argue), independently evolved larval forms? Based on a model in which the directionality of NO signaling during metamorphosis is stochastic over evolutionary time periods, there is a small probability, given current taxonomic sampling, that all larvae so far investigated would employ NO in an inhibitory manner. So either NO signaling during metamorphosis is conserved because larvae are homologous or because the use of NO in this manner during metamorphosis has been selected repeatedly. In the foundational study of NO during metamorphosis of the mud snail Illyanassa obsoleta Froggett and Leise (1999) hypothesized that the function of an inhibitory signaling system is to delay the onset of metamorphosis until chemical inducers or "cues" are detected, signaling habitats that are favorable for growth and development of the animals (Hadfield and Paul, 2001). Thus, Froggett and Leise provided a way to think about the directionality of a signal (i.e., stimulatory or inhibitory) in the context of a larval behavior that is presumably ecologically relevant and adaptive (Pechenik, 1990). It seemed as if widespread inhibitory NO function could be placed in the context of an equally widespread ecological reality.

Nobuo Ueda and Sandie Degnan at the University of Queensland in Brisbane, Australia, have shown that NO positively regulates metamorphosis in the ascidian Herdmania momus (Ueda and Degnan, 2013) and, in the present study, positively modulates (see below for the difference between a regulator and a modulator) in the abalone Haliotis asinina. Therefore, the inhibitory function of NO in metamorphosis does not appear to be a fixed character. In this current work, NO is demonstrated to serve as a necessary inductive facilitator for metamorphosis in response to a natural inducer that is needed to transduce the metamorphic chemical cue from red coralline algae Amphiroa. Although in neither study did the authors test whether NO generators could antagonize NOS inhibitors (or other "epistasis"-type experiments) and did not use a non-enzymatic method of reducing NO activity, all of their pharmacological evidence does point to a novel directionality of NO signaling and so is highly notable in this regard. Interestingly, pharmacological manipulation of NO levels alone was not sufficient to induce larval settlement and metamorphosis; NO signaling could only modulate larval responses to algal-derived settlement cues. This takes us to the second emerging aspect of studies on marine invertebrate metamorphic signaling: the relationship between the function of identified signaling pathways and ecological specialization of larval settlement.

One particular aspect of settlement ecology concerns differences in the behavior of competent larvae in the absence of settlement cues, depending upon whether larvae are settling into specialized niches or not (Elkin and Marshall, 2007; Toonen and Tyre, 2007). The "desperate larva" hypothesis, coined by Toonen and Pawlik (1994), but informed by earlier seminal experiments (Knight-Jones, 1953; Wilson, 1953) states that larvae should become less choosy about where they settle as a function of time spent in a settlementcompetent state. As a mechanism that 
explains this behavior, NO signaling is exquisitely suited to this task. The enzyme NOS consumes L-arginine, the most nitrogen rich amino acid, during the production of NO; as nutritional reserves decline, so should NO levels. In most taxa examined a reduction in NO (or cGMP in some cases) is sufficient to induce metamorphosis. By contrast, larvae having more specialized juvenile niches might be expected to be more selective in their habitat choices, therefore requiring a more robust mechanism to delay the onset of metamorphosis in the protracted absence of a settlement cue. To this end, the first evidence for a shift from regulatory to modulatory NO function was observed with the nudibranch Phestilla sibogae, a specialist carnivore on scleractinian corals in the genus Porites. In this species manipulation of NO or cGMP levels alone was not sufficient to induce metamorphosis, but NO signaling modulated settlement cues emanating from the coral (Bishop et al., 2008). Romero et al. (2013) showed that among larvae of the nudibranch Alderia willowi having low habitat selectivity that, manipulation of NO signaling by lowering $\mathrm{NO}$ levels was sufficient to induce metamorphosis while among selective larvae from the same clutch it was not sufficient. It is in this context that the results from Ueda and Degnan are particularly interesting. Ueda and Degnan have found that Haliotis asinina prefers a very specific settlement cue from Amphiroa [but see Gapasin and Polohan (2005)] and correspondingly, NO function has shifted from a positive regulatory to a positive modulatory role, providing the third instance of a correlation between larval selectivity and a shift in NO function. It would be very interesting to test the role of NO signaling in a relative to $H$. asinina ( $H$. iris, for example) whose larvae were not as selective in their choice of substrate during settlement (Roberts et al., 2004) and to extend the present observations about NO to cGMP. Finally, it is important, when designating larvae as having high or low requirements for the specificity of settlement cue, to determine larval responses to the protracted absence of such cues.

Ueda and Degnan analyzed partial sequence of a cDNA for a presumptive NOS from $H$. asinina and determined that this sequenced showed a high degree of identity with other invertebrate NOSs, indicating again the conserved and ancient use of this enzyme throughout evolution to control cellular processes. In contrast to NOS expression in other larvae where NO serves a negative regulatory role, NOS transcription was found to markedly increase during the metamorphic process in these larvae, and was notably localized to presumptive sensory cells in the anterior foot of competent larvae.

Another aspect of this work is the hypothesized relationship between the spatial pattern of NOS expression and its role as either a positive or negative modulator of metamorphosis. As put forward by Ueda and Degnan, the three different regulatory roles for $\mathrm{NO}$ in controlling the metamorphosis of marine larvae appear to be in operation in gastropod molluscs. In one role as a negative regulator, as reported for instance in Ilyanassa obsoleta and Crepidula fornicata, NOS expression occurs in the apical sensory organ, a larvalspecific sensory organ that is degraded by programmed cell death immediately after metamorphosis (Thavaradhara and Leise, 2001; Gifondorwa and Leise, 2006; Hens et al., 2006; Pechenik et al., 2007). As a negative modulator in the nudibranch Phestilla sibogae, NOS expression occurs outside of the apical sensory organ in the cerebral ganglia, pedal ganglia and sensory cells of the foot which become also part of the adult nervous system after metamorphosis (Bishop et al., 2008). In the current work, where $\mathrm{NO}$ acts as a positive facilitator, NOS expression does not occur in the apical sensory organ or central nervous system, but rather in the peripheral neural sensory system of the larval foot. This positive regulatory role for NO does not appear to be limited to the Phylum Mollusca, since Ueda and Degnan have previously found that NO acts as a positive facilitator also in the ascidian Herdmania momus, as mentioned. The spatial expression of NOS in Herdmania was not investigated however, and this species cannot be considered an ecological specialist. This apparent correlation between signal directionality and the relationship of signaling cells to the whole animal is intriguing, and future studies may help elucidate any significant advantages in having different spatial
NOS expression patterns for negative and positive regulatory roles of $\mathrm{NO}$.

From Knight-Jones' and Wilson's seminal experiments concerning larval discrimination (Knight-Jones, 1953; Wilson, 1953), to Fu-Shiang Chia's musings in about "unmasking the metamorphic factor” (Chia, 1978), to synthesis regarding larval competence and delay of metamorphosis (Pechenik, 1990; Hadfield et al., 2001) to Toonen and Tyre's (2007) and Elkin and Marshall's (2007) formal models about larval selectivity during settlement, there has been a long history of thought regarding ecology, development and evolution of larval settlement and metamorphosis. In keeping with this tradition, the present work of Ueda and Degnan has provided some food for thought and it will certainly be exciting to see, in future reports, how it all settles out.

\section{REFERENCES}

Biggers, W. J., Pires, A., Pechenik, J. A., Johns, E., Patel, P., Polson, T., et al. (2012). Inhibitors of nitric oxide synthase induce larval settlement and metamorphosis of the polychaete annelid Capitella teleta. Invertebr. Repr. Dev. 56, 1-13. doi: 10.1002/jez.1019

Bishop, C. D., Bates, W. R., and Brandhorst, B. P. (2001). Regulation of metamorphosis in ascidians involves NO/cGMP signaling and HSP90. J. Exp. Zool. 289, 374-384. doi: 10.2307/1543617

Bishop, C. D., and Brandhorst, B. P. (2001). NO/cGMP signaling and HSP90 activity represses metamorphosis in the sea urchin Lytechinus pictus. Biol. Bull. 201, 394-404. doi: 10.1093/icb/icl043

Bishop, C. D., Huggett, M. J., Heyland, A., Hodin, J., and Brandhorst, B. P. (2006). Interspecific variation in metamorphic competence in marine invertebrates: the significancel for comparative investigations into the timing of metamorphosis. Int. Comp. Biol. 46, 662-682. doi: 10.1093/icb/icl043

Bishop, C. D., Pires, A., Norby, S.-W., Boudko, D., Moroz, L. L., and Hadfield, M. G. (2008). Analysis of nitric oxide-cyclic guanosine monophosphate signaling during metamorphosis of the nudibranch Phestilla sibogae Bergh (Gastropod: Opisthobranchia). Evol. Devel. 10, 288-299. doi: 10.1111/j.1525-142X.2008.00238.x

Chia, F.-S. (1978). "Perspectives: settlement and metamorphosis of marine invertebrate," in Settlement and Metamorphosis of Marine Invertebrate Larvae, eds F.-S. Chia and M. E. Rice (New York, NY: Elsevier/North-Holland Biomedical Press), 283-285.

Comes, S., Locascio, A., Silvestre, F., d'Ischia, M., Russo, G. L., Tosti, E., et al. (2007). Regulatory roles of nitric oxide during larval development and metamorphosis in Ciona intestinalis. Dev. Biol. 306, 772-784. doi: 10.1016/j.ydbio.2007.04.016

Elkin, C., and Marshall, D. J. (2007). Desperate larvae: influence of deferred costs and habitat 
requirements on habitat selection. Mar. Ecol. Prog. Ser. 335, 143-153. doi: 10.3354/meps335143

Froggett, S. J., and Leise, E. M. (1999). Metamorphosis in the marine snail Ilyanassa obsoleta, yes or NO? Biol. Bull. 196, 57-62. doi: 10.2307/1543167

Gapasin, R. S. J., and Polohan, B. P. (2005). Response of the tropical abalone, Haliotis asinina, larvae on combinations of attachment cues. Hydrobiologia 548, 301-306. doi: 10.1007/s10750005-0754-8

Gifondorwa, D. J., and Leise, E. M. (2006). Programmed cell death in the apical ganglion during larval metamorphosis of the marine mollusk Ilyanassa obsoleta. Biol. Bull. 210, 109-120. doi: $10.2307 / 4134600$

Hadfield, M. G., Carpizo-Ituarte, E., del Carmen, K., and Nedved, B. T. (2001). Metamorphic competence, a major adaptive convergence in marine invertebrate larvae. Am. Zool. 41, 1123-1131. doi: 10.1668/0003-1569(2001)041[ 1123:MCAMAC]2.0.CO;2

Hadfield, M. G., and Paul, V. J. (2001). "Natural chemical cues for settlement and metamorphosis of marine invertebrate larvae," in Marine Chemical Ecology, eds J. B. McClintock and J. B. Baker (Boca Raton, FL: CRC Press), 431-461.

Hens, M. D., Fowler, K. A., and Leise, E. M. (2006). Induction of metamorphosis decreases nitric oxide synthase gene expression in larvae of the marine mollusk Ilyanassa obsoleta (Say). Biol. Bull. 211, 208-211. doi: 10.2307/4134543

Knight-Jones, E. W. (1953). Decreased discrimination during setting after prolonged planktonic life in larvae of Spirorbis borealis (Serpulidae). J. Mar. Biol. Assoc. U.K. 32, 337-345. doi: $10.1017 /$ S0025315400014594
Pechenik, J. A. (1990). Delayed metamorphosis by larvae of benthic marine invertebrates: does it occur? Is there a price to pay? Ophelia 32, 63-94. doi: 10.1080/00785236.1990.10422025

Pechenik, J. A., Cochrane, D. E., Li, W., West, E. T., Pires, A., and Leppo, M. (2007). Nitric oxide inhibits metamorphosis in larvae of Crepidula fornicata, the slippershell snail. Biol. Bull. 213 160-171. doi: 10.2307/25066632

Roberts, R. D., Kaspar, H. F., and Barker., R. J. (2004). Settlement of abalone (Haliotis iris) larvae in response to five species of coralline algae. J. Shell. Res. 23, 975-987.

Romero, M. R., Phuong, M. A., Bishop, C. D., and Krug, P. J. (2013). Nitric oxide signaling differentially affects habitat choice by two larval morphs of the sea slug Alderia willowi: mechanistic insight into evolutionary transitions in dispersal strategies. J. Exp. Biol. 216, 1114-1125. doi: 10.1242/jeb.080747

Thavaradhara, K., and Leise, E. M. (2001). Localization of nitric oxide-like immunoreactivity in the developing nervous system of the snail Ilyanassa obsoleta. J. Neurocytol. 30, 4498-4456. doi: 10.1023/A:1015669112986

Toonen, R. J., and Pawlik, J. R. (1994). Foundations of gregariousness. Nature 370, 511-512. doi: $10.1038 / 370511 \mathrm{a} 0$

Toonen, R. J., and Tyre, A. J. (2007). If larvae were smart: a simple model for optimal settlement behavior of competent larvae. Mar. Ecol. Prog. Ser. 349, 43-61. doi: 10.3354/meps06963

Ueda, N., and Degnan, S. M. (2013). Nitric oxide acts as a positive regulator to induce metamorphosis of the ascidian Hermania momus. PLOS ONE 8:e72797. doi: 10.1371/journal.pone.007279
Wilson, D.,P. (1953). The settlement of Ophelia bicornis Savigny larvae. The 1952 experiments. J. Mar. Biol. Assoc. U.K. 32, 209-233. doi: 10.1017/S0025315400011528

Zhang, Y., He, L.-S., Zhang, G., Xu, Y., Lee, O.-O., Matsumura, K., et al. (2012). The regulatory role of the NO/cGMP signal transduction cascade during larval attachment and metamorphosis of the barnacle Balanus (=Amphibalanus) amphitrite. J. Exp. Biol. 215, 3813-3822. doi: 10.1242/jeb.070235

Conflict of Interest Statement: The authors declare that the research was conducted in the absence of any commercial or financial relationships that could be construed as a potential conflict of interest.

Received: 28 August 2014; paper pending published: 15 September 2014; accepted: 22 September 2014; published online: 13 October 2014.

Citation: Bishop CD and Biggers WJ (2014) In Haliotis, NO means YES. Front. Mar. Sci. 1:51. doi: 10.3389/ fmars.2014.00051

This article was submitted to Marine Molecular Biology and Ecology, a section of the journal Frontiers in Marine Science.

Copyright (c) 2014 Bishop and Biggers. This is an open-access article distributed under the terms of the Creative Commons Attribution License (CC BY). The use, distribution or reproduction in other forums is permitted, provided the original author(s) or licensor are credited and that the original publication in this journal is cited, in accordance with accepted academic practice. No use, distribution or reproduction is permitted which does not comply with these terms. 